\title{
Quantitative Comparison of Mineral Ash from Agro-Industrial Waste for Use as Pozzolanic Additions in Cement: Kinetic Parameters
}

ISSN: 2578-0255

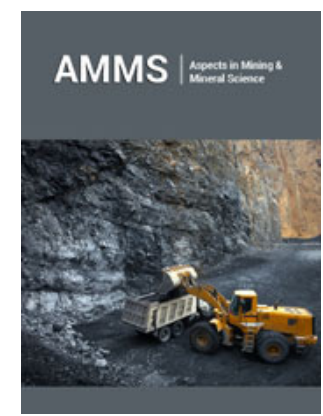

*Corresponding author: E Villar Cociña, Department of Physics, Central University of Las Villas, Santa Clara, Villa Clara, Cuba

Submission: 監 August 14, 2020

Published: 侮 September 23, 2020

Volume 5 - Issue 4

How to cite this article: Villar Cociña E, Frías Rojas M, Savastano H. Quantitative Comparison of Mineral Ash from AgroIndustrial Waste for Use as Pozzolanic Additions in Cement: Kinetic Parameters. Aspects Min Miner Sci. 5(4). AMMS. 000619. 2020.

DOI: 10.31031/AMMS.2020.05.000619

Copyright@ E Villar Cociña, This article is distributed under the terms of the Creative Commons Attribution 4.0 International License, which permits unrestricted use and redistribution provided that the original author and source are credited.

\author{
Villar Cociña $\mathrm{E}^{1}$, Frías Rojas $\mathbf{M}^{2}$ and Savastano $\mathrm{H}^{3}$ \\ ${ }^{1}$ Department of Physics, Central University of Las Villas, Cuba \\ ${ }^{2}$ Eduardo Torroja Institute (CSIC), Spain \\ ${ }^{3}$ University of Sao Paulo, Brazil
}

\begin{abstract}
In this research work a synthetic review of the quantitative characterization of various materials (sugar cane waste ashes, bamboo leaf ash, calcined paper sludge, loessic soils, zeolite, fly ash and silica fume) based on the computing of the kinetic parameters of the pozzolanic reaction in pozzolan/calcium hydroxide $(\mathrm{CH})$ systems is offered. The paper presents of more relevant results in the quantitative characterization (computing of the kinetic parameters) of the pozzolanic reaction of different materials originated from agriculture, mining or industry activities carried out by the authors.Two pozzolanic activity tests (conductometric method and accelerated chemical method) are employed. A kinetic-diffusive model (published by the authors in previous works) is used to describe the pozzolanic reaction. The kinetic parameters that characterize the process (in particular, the reaction rate constant and free energy of activation) are determined with relative accuracy in the fitting process of the model. The pozzolanic activity is quantitatively evaluated according to the results obtained for the kinetic parameters. This allows the comparison in a direct way of the pozzolanic reactivity of the materials, which is very useful for the employment of these materials for envisaged applications. The values of the reaction rate constant jointly with the free energy of activation give a precise index of the reactivity or pozzolanic activity of the materials. Complementary experimental techniques, such as X-ray diffraction (XRD) and scanning electron microscope (SEM), were also employed, but not shown in the paper for space reason since that would necessitate a much larger paper.
\end{abstract}

Keywords: Quantitative characterization; Pozzolanic activity; Kinetic parameters; Kinetic-diffusive model

Abbreviations: SCBA: Sugar Cane Bagasse Ash; SCSA: Sugar Cane Straw Ash; BLA: Bamboo Leaf Ash; CPS: Calcined Paper Sludge; LS:Loessic Soils;FA: Fly Ash; SF: Silica Fume

\section{Introduction}

Industrial by-products and wastes are attracting much research studies in recent years because of their high silica and/or alumina content for the use as additions in commercial Portland cement. It is well-known that hydrated phases formed during pozzolanic reaction commonly improve the performance of concrete [1,2]. The reuse of waste materials for concrete production is a worldwide practice. The incessant generation of solid waste materials represents serious environmental and technical problems as a consequence of several industry activities. Also, the assessment of the pozzolanic activity of cement replacement materials is becoming increasingly important because of the need for more sustainable cementing products. The majority of the wastes are disposed in landfills having an adverse effect on the environment and creating air pollution due to fine dust generation. Waste ashes as pozzolanic materials to replace cement can reduce the consumption of clinker and reduce landfill requirements. This helps solving environment problems caused by cement production, decreasing both energy used and $\mathrm{CO}_{2}$ emissions. In recent years, agro-industrial solid wastes and zeolitic minerals applied as pozzolans in the manufacture of blended mortars and concrete has become the focus of new researches on alternative binders [3-8]. In the most of these researches, the methods for evaluating pozzolanic activity of the materials are focused on the qualitative aspect of the behavior of the pozzolanic materials rather than the quantitative aspect of lime- pozzolan reaction, with the latter regarding computation of kinetic parameters. The investigation of the kinetics of pozzolanic reactions is an important experimental task that gives characteristic 
constants for the reaction rate. Using them, one can evaluate the effectiveness of applying different types of pozzolanic materials as mineral additions to mortars and concretes, as well as to compare their properties. Presently, researchers are beginning to focus on known kinetic coefficient as an acceptable and rigorous criterion for evaluating the pozzolanic activity of the materials. With this precise purpose, several traditional mathematical models have been applied to the study of the pozzolanic reaction [9-16] describing with more or less accurately the experimental results. Other authors [17-20] have continued the development of other models for the quantitative characterization of reaction kinetics in pozzolan/lime and pozzolan/cement systems.

Recently Villar Cociña et al. [21-23] proposed a kineticdiffusive model that allows characterizing the pozzolanic activity of sugarcane wastes for all ages of the reaction. The results showed a good correlation between the experimental and theoretical data what encouraged its application in the evaluation of different pozzolans. The present paper shows the principal results obtained by the authors in the quantitative characterization of various pozzolanic materials (sugar cane bagasse ash (SCBA), sugar cane straw ash (SCSA), bamboo leaf ash (BLA), calcined paper sludge (CPS), loessic soils (LS), zeolite, fly ash (FA) and silica fume (SF)) based on the computing of the kinetic parameters of the pozzolanic reaction by applying the kinetic-diffusive model especially developed for this type of evaluation. This allowed the pozzolanic activity of these materials to be characterized in a rigorous way through the computing of the kinetic parameters, which also gives the possibility of comparing in a direct way the pozzolanic behavior of the materials. The above is very useful for the selection of one or another preferred pozzolan, which will depend on the characteristics needed for the building site. Also, in the elaboration of ternary cements, of great importance in the actuality due to the present world-wide economic crisis, it is very important the knowledge of the kinetic parameters as a fundamental tool for quantifying the reactivity of the pozzolanic materials that will be added to the cement.

\section{Materials and Methods}

\section{Materials}

The materials analyzed involve both artificial pozzolan (thermally activated waste) and natural pozzolans that are readily available in industrial and agriculturally based economies. For the selection of the calcining temperature necessary for the activation of the materials the best results (high reactivity) from some research works were taken into account [23-27].

\section{Sugar cane wastes (SCW)}

The sugar cane straw (SCS) and sugar cane bagasse (SCB) were the two types of biomass recollected in the vicinity of the sugar factory "J. P. Carbó" in Villaclara, Cuba. Sugar cane straw ash (SCSA) and sugar cane bagasse ash (SCBA) were obtained in an electric furnace with controlled conditions at $800{ }^{\circ} \mathrm{C}$ calcining temperature during $20 \mathrm{~min}$. Once calcined, the ashes were ground and sieved to particle size $<90 \mu \mathrm{m}$, finesses similar to Portland cement. More information about the influence of calcining temperature on the reactivity of these materials can be found in the literature $[23,24]$.

\section{Bamboo leaf ash}

The bamboo leaves were recollected in the vicinity of the Faculty of Animal Science and Food Engineering of the Sao Paulo University, Pirassununga, State of Sao Paulo, Brazil. The bamboo leaf ashes were obtained in a laboratory electric furnace at $600{ }^{\circ} \mathrm{C}$ calcining temperature for $2 \mathrm{~h}$ of retention. Once calcined, the ashes were ground and sieved below $90 \mu \mathrm{m}$.

\section{Calcined paper sludge}

The paper waste used in this study was newsprint paper sludge with a high clay component from a newsprint paper company in Madrid, Spain, which uses exclusively recycled paper as raw material. The paper sludge was dried, and it was burnt in an electrical laboratory furnace at $600{ }^{\circ} \mathrm{C}$ during $2 \mathrm{~h}$. The activated product was cooled at room temperature and ground and sieved to below $90 \mu \mathrm{m}$. More information about the influence of calcining temperature on the activation of this material can be found in reference [25].

\section{Loessic soil}

Quintana and Villar-Cociña performed a study of loessic soils. A typical stratigraphical column of Pampean Loessic sediments, located at center of Cordoba Province, Argentina, was sampled. Diverse layers of loess were identified. In this paper only the intermediate layer was chosen, $5.50 \mathrm{~m}$ thick, with sandy layers and cemented layers of loess. More information about the characteristics of the different layers can be found in reference [28].

\section{Zeolite}

Rosell-Lam and Villar-Cociña studied a Cuban zeolite. A natural zeolitic rock from Tasajeras deposits situated in province of Villaclara, Cuba was used. The zeolite was ground and sieved to below $90 \mu \mathrm{m}$, with grain size average of $84.8 \mu \mathrm{m}$. More information about the influence of grain size on the pozzolanic activity can be found in Rosell-Lam et al. [29].

\section{Fly ash}

The fly ash was originated in the burning process of mineral coal-fired thermoelectrical plant, located in Capivari de Baixo, Santa Catarina Estate, Brazil. Such ash is produced in an electrostatic precipitator and corresponds to about $80 \mathrm{wt} \%$ of the total ashes generated for this station. The ashes have a fine granulometry below $90 \mu \mathrm{m}$ with average grain size of $49.7 \mu \mathrm{m}$.

\section{Silica fume}

The silica fume used in the study was supplied from Elkem Co., Ltd. (Sao Paulo, Brazil). Elkem Microsilica has an 85-98\% amorphous silicon dioxide $\left(\mathrm{SiO}_{2}\right)$ in the form of microscopic spherical particles. According to the supplier company (Elkem Microsilica), the average diameter of these particles is $0.1-0.15 \mu \mathrm{m}$ [30]. Table 1 shows the samples designations and the activation conditions. 
Table 1: Designations of the samples used.

\begin{tabular}{|c|c|}
\hline Samples & Designations \\
\hline Sugar cane straw ash (calcined at $800^{\circ} \mathrm{C}$ ) & SCSA \\
\hline Sugar cane bagasse ash (calcined at $800^{\circ} \mathrm{C}$ ) & SCBA \\
\hline Bamboo leaf ash (calcined at $600^{\circ} \mathrm{C}$ ) & BLA \\
\hline Calcined Paper sludge (Calcined at $600^{\circ} \mathrm{C}$ ) & CPS \\
\hline Fly ash (uncontrolled temperature) & FA \\
\hline Loessic soil (natural pozzolan) & LS \\
\hline Zeolite (natural pozzolan) & Zeolite \\
\hline Silica Fume (uncontrolled temperature) & SF \\
\hline
\end{tabular}

\section{Lime}

The lime used in the pozzolan/calcium hydroxide system was an analytical grade calcium hydroxide $(95 \%$ of minimum purity, $4.8 \%$ of maximum magnesium and alkaline salts content, and $0.5 \%$ of maximum insoluble substance content).

\section{Test Methodologies}

\section{Pozzolanic activity methods}

To carry out a qualitative or quantitative determination of pozzolanic activity many experimental methodologies have been developed [31-34]. In this research, as in other studies carried out by the authors $[25,26,35,36]$ two different pozzolanic activity methods were applied. Both methods are based in the monitoring of the lime consumption with the reaction time and they can be used indistinctly. The computing of the kinetic parameters of the pozzolanic reaction by applying the kinetic-diffusive model that will be used in this research is independent of the method used for the evaluation of the pozzolanic activity as it was demonstrated elsewhere [35].

\section{Conductometric method}

This method follows the conductivity of the pozzolan-calcium hydroxide solution with reaction time. A saturated solution of calcium hydroxide $(\mathrm{CH})$, prepared with deionized water and $\mathrm{Ca}(\mathrm{OH})_{2}$ was used. The $\mathrm{Ca}(\mathrm{OH})_{2}$ in excess was mixed with deionized water and stirred for $2 \mathrm{~h}$, after which the solution was maintained at rest for $24 \mathrm{~h}$. Thereafter, the solution was filtered, and it was valued with hydrochloric acid $(\mathrm{HCl})$. Each $100 \mathrm{ml}$ of saturated $\mathrm{Ca}(\mathrm{OH})_{2}$ solution were mixed with $2.10 \mathrm{~g}$ of pozzolanic material (which is the proportion commonly found in the literature for similar experiments) and magnetically stirred. Immediately after the pozzolan was mixed with the $\mathrm{CH}$ solution, the conductivity measurements began. The measurements of conductivity were made at $40 \pm 1^{\circ} \mathrm{C}$ at different times. To correlate the $\mathrm{CH}$ concentration with the conductivity of the $\mathrm{CH}$ solution a calibration curve that demonstrates a linear dependence, was applied [21,28,34].

\section{Accelerated chemical method}

This method also follows the pozzolan-calcium hydroxide reaction over time. The test consisted of putting the pozzolanic material $(1 \mathrm{~g})$ in contact with a saturated lime solution $(75 \mathrm{~mL})$ at
$40 \pm 1{ }^{\circ} \mathrm{C}$ for $1,7,28$ and 90 days. At the end of each period, $\mathrm{CaO}$ (quicklime) concentration in the solution was analyzed. The fixed calcium hydroxide (mmol/L) was obtained as the difference between the original concentration of a solution of saturated calcium hydroxide and the $\mathrm{CaO}$ found in the solution in contact with the sample, at the end of a given period [36].

\section{Mathematical model}

It is known that the pozzolanic reaction in $\mathrm{CH} /$ pozzolan systems is heterogeneous and it can be considered about solidsolution type:

$$
\mathrm{A}_{(\mathrm{L})}+\mathrm{bB}_{(\mathrm{S})} \rightarrow \mathrm{F}_{(\mathrm{S})}+\mathrm{E}_{(\mathrm{L})}
$$

When solution A reacts on the surface of the solid reactant $B$ (with stoichiometry coefficient $b$ ) a layer of reaction products $F$ is formed around the nucleus of reactant B that has not yet reacted (unreacted nucleus within) which decreases gradually. If the layer $\mathrm{F}$ is porous the reaction takes place by diffusion of A through the layer $\mathrm{F}$ until it is verified on the interface between $\mathrm{F}$ and the nucleus without reacting. $\mathrm{E}_{(\mathrm{L})}$ accounts for the fluid products of the solidsolution type reaction that could be formed. The form of the rate equation is determined by the control regime or the rate-limiting step which can be one of the following two, principally [37,38]: (1) diffusion through the layer of reaction product (diffusive control), (2) chemical reaction at the surface on the unreacted nucleus (kinetic control). Villar Cociña et al. [21,22] proposed a kineticdiffusive model for describing the pozzolanic reaction in sugar cane straw-clay ash/CH systems. Thereafter, for the case of sugar cane straw ash/CH and sugar cane bagasse ash/Ch systems, a correction term $\left(\mathrm{C}_{\text {corr }}\right)$ was added to the model to account for the remaining concentration of $\mathrm{CH}$ that is not consumed in the reaction. In some systems the $\mathrm{CH}$ is not consumed totally. The corrected model is [23]:

$$
\xi=\frac{C_{0}-C_{t}}{C_{0}}=1-\frac{0,23 \cdot \operatorname{Exp}\left(\frac{-3 t}{\tau}\right) \cdot\left(-1+\operatorname{Exp}\left(\frac{t}{\tau}\right)\right) \cdot \frac{1}{\tau}}{C_{0} D_{e} r_{s}}+\frac{0,23 \cdot \operatorname{Exp}\left(\frac{-t}{\tau}\right) \cdot \frac{1}{\tau}}{C_{0} K r_{s}^{2}}-C_{c o r r}
$$

where $\mathrm{D}_{\mathrm{e}}$ is the effective diffusion coefficient of $\mathrm{A}$ through the porous layer of product $\mathrm{F}, \mathrm{K}$ is the reaction rate constant, $\mathrm{C}_{\mathrm{o}}$ is the initial concentration of the solution and $\tau$ is a constant of time (time interval in which the radius of the nucleus of pozzolan diminish to $37 \%$ of its initial radius $\left(r_{s}\right)$ ). The radius $r_{s}$ of the pozzolan particles was taken as the average size particle for each analyzed material. The dimensionless magnitude $\xi=\left(C_{0}-C_{t}\right) / C_{0}$ represents the relative loss of lime concentration and $C_{t}$ represents the absolute loss of lime concentration with time for the pozzolan/CH system. As the pozzolanic reaction develops in stages, it is possible that the ratelimiting stage corresponds with the diffusion through the layer of reacting product or with the chemical reaction at the surface on the unreacted nucleus. For that reason, it is possible in certain cases to have different behavior: diffusive (described by the $2^{\text {nd }}$ term of Eq.(1)), kinetic ( $3^{\text {rd }}$ term) and kinetic-diffusive $\left(2^{\text {nd }}\right.$ and $3^{\text {rd }}$ terms). Further explanations about the model can be found elsewhere $[21,22]$. The fitting of this model allows determining the 
kinetic parameters (effective diffusion coefficient and reaction rate constant) and, therefore, a rigorous characterization of the process.

\section{Results and Discussion}

\section{Chemical characterization}

The chemical compositions of the ashes were determined by an X-ray fluorescence (XRF) technique (Table 2). The main oxide present in SCSA and SCBA ashes is $\mathrm{SiO}_{2}$, followed by CaO. Other oxides such as $\mathrm{Al}_{2} \mathrm{O}_{3}, \mathrm{Fe}_{2} \mathrm{O}_{3}, \mathrm{~K}_{2} \mathrm{O}$ and $\mathrm{SO}_{3}$ are present in smaller amounts. In the case of the zeolite the main oxides present are $\mathrm{SiO}_{2}$ (about 67\%), followed of $\mathrm{Al}_{2} \mathrm{O}_{3}$ (about 12\%). Other oxides such as $\mathrm{Fe}_{2} \mathrm{O}_{3}, \mathrm{CaO}, \mathrm{Na}_{2} \mathrm{O}$ and $\mathrm{MgO}$ are present in small amounts. For FA the main oxides present (Table 2) are: $\mathrm{SiO}_{2}$ as the major component in ash following $\mathrm{Al}_{2} \mathrm{O}_{3}, \mathrm{Fe}_{2} \mathrm{O}_{3}, \mathrm{CaO}$ and $\mathrm{TiO}_{2}$. The rest of the oxides were below $0.5 \%$. The main oxide present in BLA and SF ashes is $\mathrm{SiO}_{2}$ with a percentage of 80.4 and $87.4 \%$ respectively, followed by $\mathrm{CaO}(5.06 \%), \mathrm{Al}_{2} \mathrm{O}_{3}(1.22 \%)$ for Blash and $\mathrm{MgO}$ (2.81\%) and $\mathrm{Fe}_{2} \mathrm{O}_{3}$ $(2.13 \%)$ for SF. Other oxides are present in both samples in smaller amount.

Table 2: Chemical composition of the pozzolans analyzed.

\begin{tabular}{|c|c|c|c|c|c|c|c|c|}
\hline Oxide (\%) & SCSA & SCBA & BLA & CPS & LS & Zeolite & FA & SF \\
\hline $\mathrm{SiO}_{2}$ & 70.2 & 58.61 & 80.4 & 20.94 & 62.2 & 66.78 & 60.1 & 87.5 \\
\hline $\mathrm{Al}_{2} \mathrm{O}_{3}$ & 1.93 & 7.32 & 1.22 & 13.86 & 13.19 & 11.89 & 24 & 0.51 \\
\hline $\mathrm{Fe}_{2} \mathrm{O}_{3}$ & 2.09 & 9.45 & 0.71 & 0.51 & 4.65 & 4.04 & 6.7 & 2.13 \\
\hline $\mathrm{CaO}$ & 12.20 & 12.56 & 0.99 & 35.06 & 4.39 & 3.32 & 1.6 & 0.45 \\
\hline $\mathrm{MgO}$ & 1.95 & 2.04 & 5.06 & 2.36 & 1.46 & 0.45 & 0.37 & 2.81 \\
\hline $\mathrm{SO}_{3}$ & 4.10 & 0.53 & 1.07 & 0.28 & 0.25 & 0.25 & 0.26 & 0.79 \\
\hline $\mathrm{K}_{2} \mathrm{O}$ & 3.05 & 3.22 & 1.33 & 0.39 & 1.81 & 0.97 & 2.53 & 2.15 \\
\hline $\mathrm{Na}_{2} \mathrm{O}$ & 0.50 & 0.92 & 0.08 & 0.06 & 3.10 & 1.22 & 0.35 & 2.55 \\
\hline $\mathrm{TiO}_{2}$ & 0.02 & 0.34 & 0.1 & 0.26 & 0.26 & 0.02 & 1.39 & \\
\hline $\mathrm{P}_{2} \mathrm{O}_{5}$ & & & & & & & & $<0.001$ \\
\hline $\mathrm{LOI}$ & 1.81 & 2.73 & 8.04 & 25.9 & na & 10.36 & 2.03 & 0.62 \\
\hline
\end{tabular}

SCSA=Sugar Cane Straw Ash; SCBA=Sugar Cane Bagasse Ash; BLA=Bamboo Leaf Ash; CPS=Paper Sludge; FA=Flay Ash; SF= Silica Fume; NA=Not Applicable

\section{Pozzolanic activity}

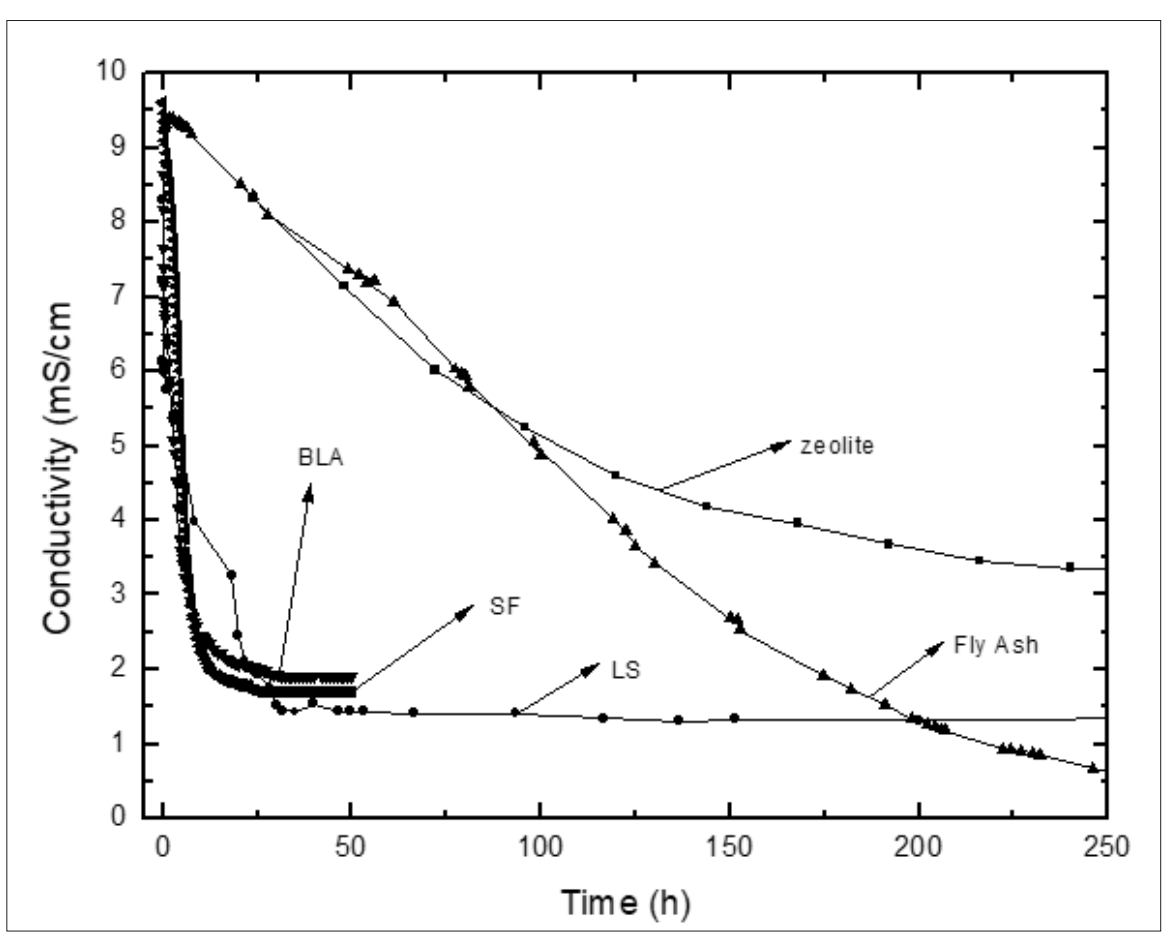

Figure 1: Variation of conductivity with reaction time for zeolite, loessic soil (LS), fly ash (FA) bamboo leaf ash (BLA) and silica fume (SF). 


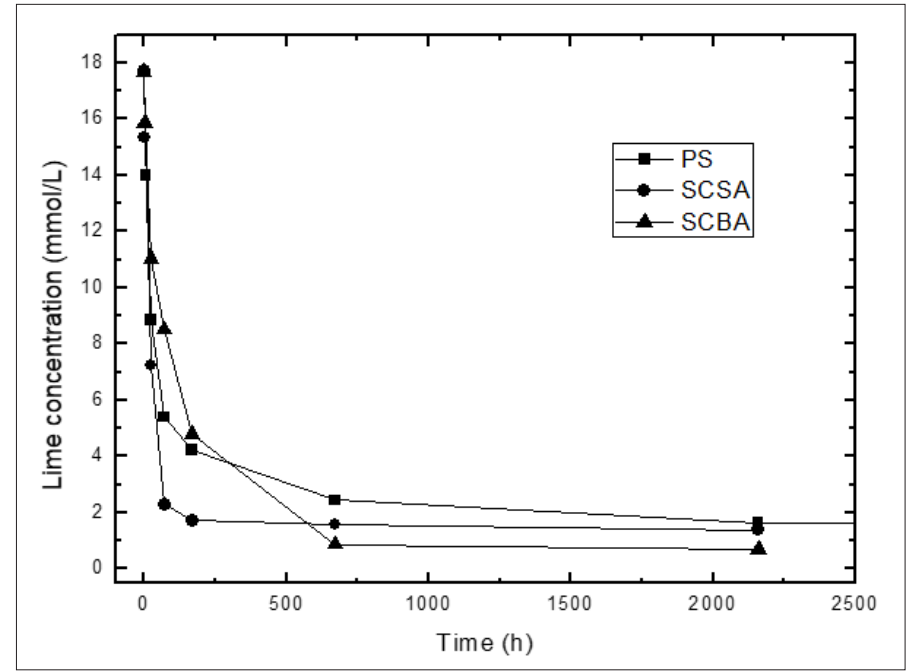

Figure 2: Variation of lime concentration with reaction time for calcined paper sludge (CPS), sugar cane straw ash (SCSA) and sugar cane bagasse ash (SCBA).

The results obtained for pozzolanic activity are shown in Figures $1 \& 2$. In (Figure 1) the conductivity variations versus time for the pozzolans/CH suspensions are shown for zeolite, LS, FA, BLA and SF pozzolans; while Figure 2 shows the results of accelerated pozzolanic tests for CPS, CSCA and CSBA ones up to 90 days of reaction. In the present study there was no influence of the pozzolanic activity methods on the computing of the kinetic parameters [35]. The conductometric test (Figure 1) showed a decrease of the electrical conductivity of the suspensions. This behavior was attributed to the formation of hydrated phases with the corresponding decrease of the $\mathrm{CH}$ concentration in the solution, which leads to a decrease in conductivity. A considerable variation (loss) of conductivity in early ages is obtained; is evident that SF consumes more $\mathrm{CH}$ than the BLA. However, a high reactivity of BLA is appreciated from the qualitative point of view comparable to SF, a highly expensive pozzolan, followed by LS, FA and zeolite. The stabilization to the curve is rapidly reached for SF and BLA (only $30 \mathrm{~h}$ are needed approximately), followed by LS. For the other materials, the stabilization of the curve is reached for long times. This indicates the moment when the reaction has finished practically.

According with the above-mentioned it might be possible to conclude that a greater reactivity is qualitatively observed for SF and BLA, followed by LS, FA and zeolite. However, another important factor that must be taken into account when an evaluation of the reactivity is carried out is the difference between the initial and final conductivities (stabilized electrical conductivity) in the different pozzolan/CH solutions (a major difference, the reactivity of the material will be higher [3]). This could be related with the amount consumed of calcium hydroxide, a great difference corresponds to a greater consume of $\mathrm{CH}$ in comparison with a minor difference. For example, for the case of the materials shown in Figure 1 it is evident that FA consumes more CH than the LS but does not provide information on the rapidity of the reaction. It is clear that qualitatively is very difficult to have an accurate idea of the pozzolanic activity. For that reason, an evaluation from the point of view quantitative of the pozzolanic reactivity that involves all this aspects and that allows the computation of the kinetic parameters is very important. On the other hand, the results of accelerated pozzolanic tests for reaction times of up to 90 days are shown in Figure 2. The absolute loss of lime concentration plotted against reaction time for the pozzolans/CH samples is shown. A considerable loss of lime concentration in early ages is obtained for all samples (SCSA, SCBA and CPS). The stabilization of the curve was reached after long period of time and it depends on the analyzed sample. A qualitative analysis shows a greater reactivity for SCSA followed by SCBA and CPS. This fact could be related to the higher alumina content in CPS than for SCSA and CSBA respectively, forming also hexagonal plaques of calcium aluminates $\left(\mathrm{C}_{4} \mathrm{AH}_{13}\right)$ [39].

\section{Application of the mathematical model and determina- tion of the kinetic parameters}

As above-mentioned, the knowledge of the kinetic parameters of the pozzolanic reaction is a good criterion for evaluating quantitatively the pozzolanic activity of the materials. In the international bibliography the values reported of kinetic parameters for pozzolan/CH solution are very scarce. We have not encountered in the literature at our disposal any attempt of reporting kinetic parameters for various pozzolanic materials that give the possibility of comparing quantitatively the reactivity of same ones. With the aim of computing the kinetic parameters, the kinetic-diffusive model (Eq. (1)) was applied for all samples. (Figures 3-6) illustrate the relative loss of lime concentration plotted against reaction time for SCSA/CH, SCBA/CH, CPS/CH, $\mathrm{LS} / \mathrm{CH}$, zeolite/CH, FA/CH and BLA/CH and SF/CH respectively. The solid and dash lines represent the curves of the fitted model. Fitting the relative loss of lime concentration versus reaction time successively to the kinetic control model, diffusive control model and a mixed (kinetic-diffusive) control model and carrying out an 
exhaustive analysis of the important statistical parameters such as correlation coefficient ( $\mathrm{r}$ ), coefficient of multiple determination $\left(\mathrm{R}^{2}\right)$, 95\% confidence intervals, residual sum of squares (RSS), residual scatter, residual probability and variance analysis, it can be stated that for the case of SCSA, SCBA, BLA, CPS and LS the kinetic control model shows the best correspondence with the experimental data. This means that the chemical interaction speed on the surface of the nucleus of the pozzolan particle is slower than the diffusion speed of the reactant through the reaction product layer formed around the nucleus. This might be due to the high porosity of the reaction product layer in these materials, which facilitates a quick diffusion process [40]. For the samples of zeolite, FA and SF, a kinetic-diffusive control regime predominated showing the best correspondence with the experimental data. This means that the chemical interaction speed on the surface of the nucleus of the pozzolan particle was comparable with the diffusion speed of the reactant through the reaction product layer around the nucleus. Therefore, both processes determine the general speed of the whole process. The values of the parameters ( $\tau$, and $\mathrm{K}$ ) are given in Table 3. Taking into account the values of the kinetic parameters it is possible to conclude that both BLA and SF have a very high and similar reactivity. The silica fume has a reactivity slightly higher (larger $\mathrm{K}$, but of the same order) than the BLA calcined at $600{ }^{\circ} \mathrm{C}$. The pozzolanic reactivity for SF and BLA calcined at $600{ }^{\circ} \mathrm{C}$ show the highest reactivity (larger value of K) followed by FA, SCSA, SCBA, LS, CPS and zeolite. These results agree with the qualitative analysis carried out previously in the "Pozzolanic activity section" above.

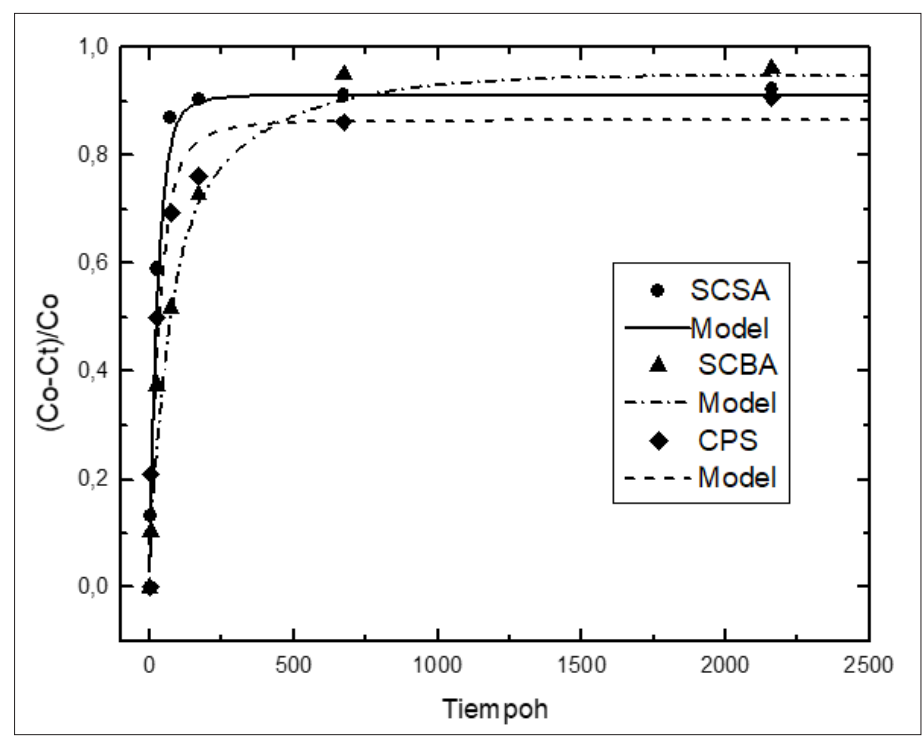

Figure 3: Relative loss of lime concentration versus reaction times for SCSA, SCBA and CPS. Black circle (experimental), solid, dash and dots line (model).

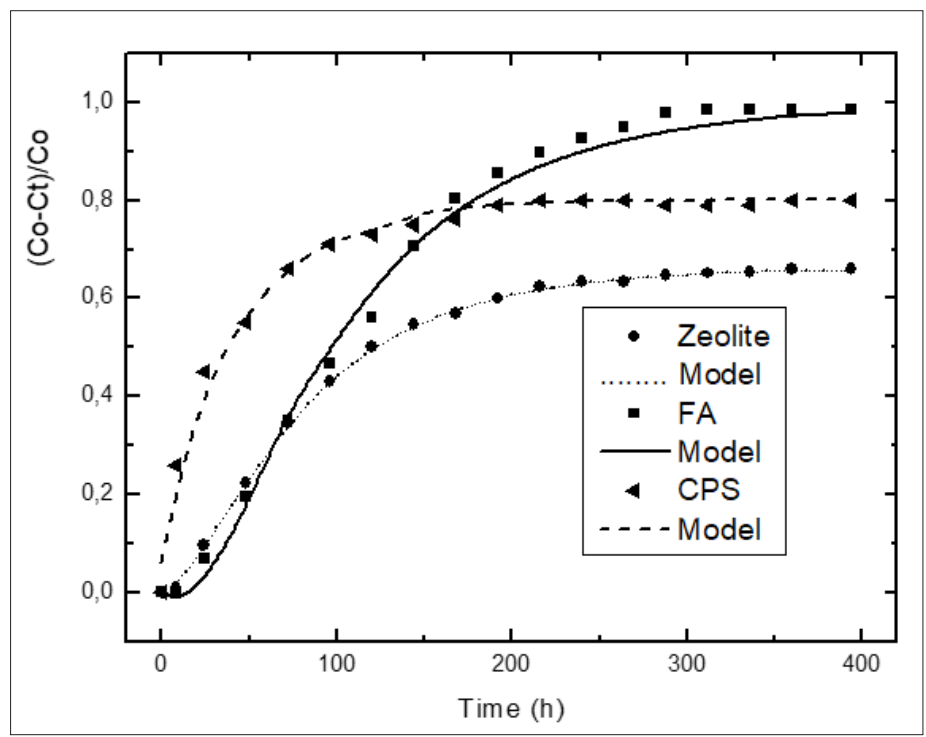

Figure 4: Relative loss of conductivity versus reaction times for Zeolite, FA and CPS Black circle (experimental), solid, dash, and dote line (model). 


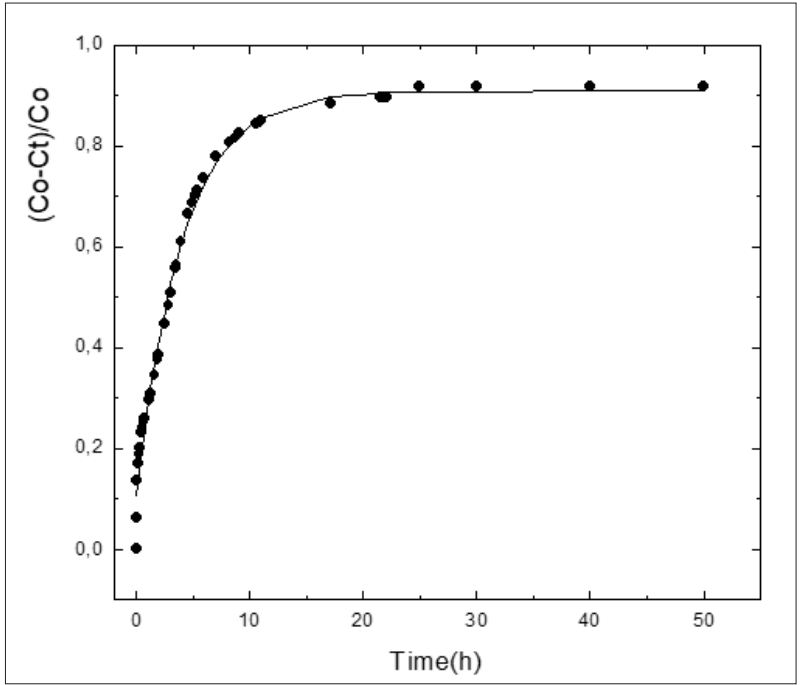

Figure 5: Relative loss of conductivity versus reaction times for BLA. Black circle (experimental), solid line (model).

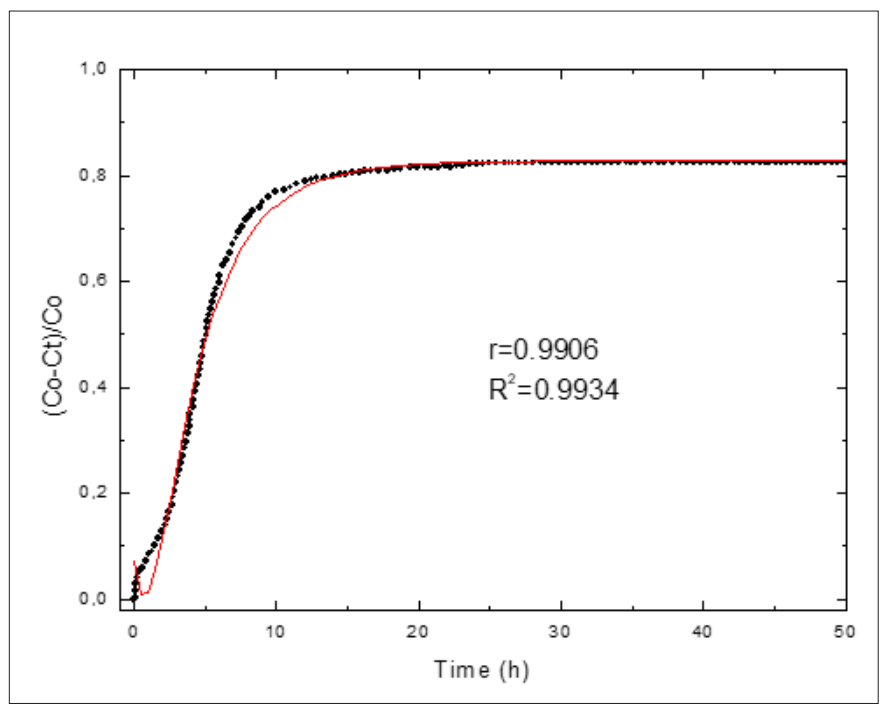

Figure 6: Relative loss of conductivity versus reaction times for SF. Black circle (experimental), solid line (model).

Table 3: Reaction rate constants, $\tau$ parameter, free energy of activation, Ccorr. parameter and statistical parameters for the pozzolanic materials.

\begin{tabular}{|c|c|c|c|c|c|c|}
\hline Material (Ash) & $\boldsymbol{\tau}(\mathbf{h})$ & $\begin{array}{c}\text { Reaction Rate Con- } \\
\mathbf{s t a n t}\left(\mathbf{h}^{-1}\right)\end{array}$ & $\mathbf{C}_{\text {corr. }}$ & $\begin{array}{c}\text { Correlation } \\
\text { Coefficient (r) }\end{array}$ & $\begin{array}{c}\text { Coefficient of Multi- } \\
\text { ple Determination } \\
\mathbf{( R}^{2} \mathbf{)}\end{array}$ & $\begin{array}{c}\text { Residual Sum of } \\
\text { Squares }\end{array}$ \\
\hline SCSA & $23.3 \pm 1.8$ & $(8.11 \pm 0.67) \cdot 10^{-2}$ & $0.088 \pm 0.012$ & 0.9988 & 0.9976 & 0.0022 \\
\hline SCBA & $100.3 \pm 9.8$ & $(1.91 \pm 0.38) \cdot 10^{-2}$ & $0.051 \pm 0.038$ & 0.9894 & 0.9788 & 0.002 \\
\hline BLA & $4.1 \pm 0.2$ & $(4.78 \pm 0.09) \cdot 10^{-1}$ & $0.09 \pm 0.008$ & 0.9958 & 0.9916 & 0.0293 \\
\hline CPS & $34.8 \pm 3.4$ & $(8.69 \pm 0.94) \cdot 10^{-3}$ & $2.39 \pm 0.51$ & 0.9860 & 0.9722 & 0.0062 \\
\hline LS & $48.4 \pm 4.6$ & $(1.23 \pm 0.21) \cdot 10^{-2}$ & $0.19 \pm 0.01$ & 0.9925 & 0.9851 & 0.037 \\
\hline Zeolite & $78.1 \pm 1.6$ & $(6.88 \pm 0.24) \cdot 10^{-3}$ & $3.09 \pm 0.02$ & 0.9998 & 0.9996 & 0.0002 \\
\hline FA & $101.9 \pm 1.7$ & $(1.76 \pm 0.04) \cdot 10^{-1}$ & $0.01 \pm 0.004$ & 0.9972 & 0.9943 & 0.0595 \\
\hline SF & $4.1 \pm 0.1$ & $(5.11 \pm 0.08) \cdot 10^{-1}$ & $0.17 \pm 0.003$ & 0.9906 & & 0.0634 \\
\hline
\end{tabular}




\section{Conclusion}

a. Chemically, all samples are formed by the same oxides but with different contents. The main oxides are silica and alumina (although CPS shows a 35\% of $\mathrm{CaO}$ ) whose contents are: $88.01 \%$ (SF), 84.1\% (FA), 81.62\% (BLA), 78.67\% (zeolite), 75.39\% (LS), $72.13 \%$ (SCSA), $65.93 \%$ (SCBA) and $34.80 \%$ (CPS)

b. The values of the reaction rate constant, obtained in the fitting process of the kinetic-diffusive model, show that silica fume and the bamboo leaves ashes (calcined at $600^{\circ} \mathrm{C}$ ) have a very high pozzolanic reactivity, followed by FA, SCSA, SCBA, LS, CPS and zeolite.

c. The assessment from the quantitative point of view of the pozzolanic reactivity through the calculation of the kinetic parameters allows a direct comparison between different pozzolanic materials. According to the values calculated of the reaction rate constant $\mathrm{K}$, silica fume and bamboo leaf ashes show the highest reactivity $\left(5.11 .10^{-1} \mathrm{~h}^{-1}\right)$ and $\left(4.78 .10^{-1} \mathrm{~h}^{-1}\right)$ respectively, followed by fly ash $\left(1.76 .10^{-1} \mathrm{~h}^{-1}\right)$, sugar cane straw ash $\left(8.11 .10^{-2} \mathrm{~h}^{-}\right.$ $\left.{ }^{1}\right)$, sugar cane bagasse ash $\left(1.91 .10^{-2} \mathrm{~h}^{-1}\right)$, loessic soil $\left(1.23 .10^{-2} \mathrm{~h}^{-1}\right)$, calcined paper sludge $\left(8.69 .10^{-3} \mathrm{~h}^{-1}\right)$ and zeolite $\left(6.88 .10^{-3} \mathrm{~h}^{-1}\right)$.

d. The availability of materials with different pozzolanic reaction rates can become an important technological advantage in the manufacture of new blended cements that include both natural pozzolans as thermally activated materials. The selection of one addition or another as the preferred pozzolan will depend on the characteristics needed for the building site.

\section{Acknowledgement}

The authors thank FAPESP (Brazil) (process 2011/126912) and CNPq (Brazil) (401704/2013-0 and 306386/2013-5) for the financial support to carry out and to conclude this research work. Also, the authors would like to thank the FAPESP (process n. 2011/16842-5) and to CSIC-FAPESP program (i-Link+2013, project ref: i-link0675, 2013/50790-8) for their financial support, and to the Framework Agreement of Collaboration between IETcc/ CSIC (Spain) and FZEA/USP (Brazil) (ref: BDC 20195707 ACAM 2019040029).

\section{References}

1. Massazza F (1976) Chemistry of pozzolanic additions and mixed cement Il Cemento 73(1): 3-39.

2. Metha PK (1998) Role of cementitious material in sustainable development of the concrete industry. In: Malhotra VM (Ed.), Proceeding of the Sixth CANMET/ACI Inter Conf on the Fly ash, Silica fume, Slag and Natural Pozzolans in Concrete, SP-178, Bangkok. 1: 1-20.

3. Sinthaworn S, Nimityongskul P (2009) Quick monitoring of pozzolanic reactivity of waste ashes. Waste Manage 29(5): 1526-1531.

4. Ahmadi B, Shekarchi M (2010) Use of natural zeolite as a supplementary cementitious material. Cem Concr Comp 32(2): 134-141.

5. Uzal B, Turanli L, Yücel H, Göncüoglu MC, Çulfaz A (2010) Pozzolanic activity of clinoptilolite: A comparative study with silica fume, fly ash and a non-zeolitic natural pozzolan. Cem Concr Res 40(3): 398-404.
6. Nair DG, Fraaij A, Klaassen AAK, Kentgens APM (2008) A structural investigation relating to the pozzolanic activity of rice husk ashes. Cem Concr Res 38(6): 861-869.

7. Rukzon S, Chindaprasirt P (2012) Utilization of bagasse ash in highstrength concrete. Materials and Design 34: 45-50.

8. Narasimhulu K, Gettu R, Ganesh B (2014) Beneficiation of natural zeolite through flash calcination for its use as a mineral admixture in concrete. J Mater Civ Eng 26(1): 24-33.

9. Khangaonkar PR, Rahmat A, Jolly KG (1992) Kinetic study of the hydrothermal reaction between lime and rice-husk-ash silica. Cem Concr Res 22(4): 577-588.

10. Frías M, Cabrera J (2002) The effect of temperature on the hydration rate and stability of the hydration phases of metakaolin-lime-water systems. Cem Concr Res 32: 133-138.

11. Jander W (1927) Solid state reactions at higher temperature. Allg Chem 163(1-2): 1-30.

12. Kondo R, Lee K, Diamond M (1976) Kinetics and mechanism of hydrothermal reaction in lime-quartz-water systems. J Ceram Soc Jpn 84(975): 573-578.

13. Browers HJH, Van Eijk RJ (2002) Fly ash reactivity: Extension and application of a shrinking core model and thermodynamic approach. J Mater Sci 37: 2129-2141.

14. Ninov J, Dimova L, Doykov I, Petrov B, Brakalov L (2011) On the kinetics of pozzolanic reaction in metakaolin-lime-water system. J Therm Anal Calorim 105(1): 245-250.

15. Rao S, Asha K (2012) Activation of fly ash-lime reactions: Kinetic approach. J Mater Civ Eng 24(8): 1110-1117.

16. Wang XY (2013) Evaluation of compressive strength of hardening silica fume blended concrete. J Mater Sci 48: 5953-5961.

17. Glosser D, Suraneni P, Burkan O, Isgor W, Weiss J (2020) Estimating reaction kinetics of cementitious pastes containing fly ash. Cement and Concrete Composites 112: 103655.

18. Valentini L, Favero M, Dalconi MC, Russo V, Ferrari G, et al. (2016) Kinetic model of calcium-silicate hydrate nucleation and growth in the presence of PCE superplasticizers. Crystal Growth \& Design 16(2): 646-654.

19. Frías M, Vigil de la Villa R, Martínez Ramírez S, Fernández Carrasco L, Villar Cociña E, et al. (2020) Multi-technique characterization of a fine fraction of CDW and assessment of reactivity in a CDW/lime system. Minerals 10(7): 590.

20. Honorio T, Bary B, Benboudjema F, Poyet S (2016) Modeling hydration kinetics based on boundary nucleation and space-filling growth in a fixed confined zone. Cement and Concrete Research 83: 31-44.

21. Villar Cociña E, Valencia Morales E, Gonzalez Rodriguez R, Hernandez Ruiz J (2003) Kinetics of the pozzolanic reaction between lime and sugar cane straw ash by electrical conductivity measurement: A kineticdiffusive model. Cem Concr Res 33: 517-524.

22. Villar Cociña E, Frías M, Valencia Morales E, Sánchez de Rojas MI (2006) An evaluation of different kinetic models for determining the kinetic coefficients in sugar cane straw-clay ash/lime system. Adv Cem Res 18(1): 17-26.

23. Villar Cociña E, Frías M, Valencia Morales E (2008) Sugar cane wastes as pozzolanic materials: Application of mathematical model. ACI Mater J 105: 258-264.

24. Frías M, Villar Cociña E, Valencia Morales E (2007) Characterization of sugar cane straw as pozzolanic materials for construction: Calcining temperature and kinetic parameters. Waste Manage 27(4): 533-538. 
25. Frias M, Rodriguez O, Nebreda B, Garcia R, Villar Cociña E (2010) Influence of activation temperature of kaolinite based clay wastes on pozzolanic activity and kinetic parameters. Adv Cem Res 22(3): 135142.

26. Frías M, García R, Vigil R, Ferreiro S (2008) Calcination of art paper sludge waste for the use as a supplementary cementing material. App Clay Sci 42(1-2): 189-193.

27. Frías M, Villar Cociña E (2007) Influence of calcining temperature on the activation of sugar-cane bagasse: kinetic parameters. Adv Cem Res 19(3): 109-115.

28. Quintana Crespo E, Villar Cociña E (2011) A kinetic study about the pozzolanic reactivity of loessic soils by conductometric methods: kinetic parameters. Adv Cem Res 23(1): 3-10.

29. Rosell Lam M, Villar Cociña E, Frias M (2011) Study on the pozzolanic properties of a natural Cuban zeolitic rock by conductometric method: Kinetic parameters. Constr Build Mater 25: 644-650.

30. Villar Cocina E, Rodier L, Savastano H, Lefran M, Frias M (2020) A comparative study on the pozzolanic activity between bamboo leaves ash and silica fume: kinetic parameters. Waste and Biomass Valorization 11: $1627-1634$.

31. British Standard Euronorm (BS EN) 196 (2005) Methods of testing cement. Part 5: pozzolanicity test for pozzolanic cement.

32. American Society for Testing and Materials (ASTM) C-311 (2005) Standard test methods for sampling and testing fly ash or natural pozzolans for use in Portland-cement concrete, USA.
33. Donaatello S, Tyrer M, Cheeseman CR (2010) Comparison of test methods to assess pozzolanic activity. Cem Concr Compos 32(2): 121127.

34. Villar Cociña E, Frías M, Morales EV, Savastano H (2009) Study of the pozzolanic reaction kinetics in sugar cane bagasse-clay ash/calcium hydroxide system: Kinetic parameters and pozzolanic activity. Adv Cem Res 21(1): 23-30.

35. Frías M, Villar Cociña E, Sánchez de Rojas MI, Valencia Morales E (2005) The effect of different pozzolanic activity methods on the kinetics constants of the pozzolanic reaction: Application of a kinetic-diffusive model. Cem Concr Res 35(11): 2137-2142.

36. Rodríguez O, Frías M, Sánchez de Rojas MI (2008) Influence of the calcined paper sludge on the development of hydration heat in blended cement mortars. J Therm Anal Cal 92: 865-871.

37. Levenspiel 0 (1999) Chemical Reaction Engineering. Wiley, New York.

38. Renedo MJ, Fernández J (2004) Kinetic modeling of the hydrothermal reaction of fly ash, $\mathrm{Ca}(\mathrm{OH})_{2}$ and $\mathrm{CaSO}_{4}$ in the preparation of desulphurant sorbents. Fuel 83: 525-532.

39. Rodríguez O, Vigil de la Villa R, García R, Nebreda B, Frías M (2011) Lower temperature activation for kaolinite-based clay waste: Evaluation of hydrated phases during the pozzolanic reaction. J Am Ceram Soc 94(4): 1224-1229.

40. Morales EV, Villar Cociña E, Frías M, Santos SF, Savastano H (2009) Effects of calcining conditions on the microstructure of sugar cane waste ashes (SCWA): Influence in the pozzolanic activation. Cement \& Concrete Composites 31(1): 22-28. 